\title{
Obstetrics knowledge and skills training as a catalyst for change
}

\author{
R C Pattinson, ${ }^{1,2}$ FRCOG, MD, FCOG (SA), MMed, MB BCh, BSc; A-M Bergh, ${ }^{1}$ PhD; J Makin, ${ }^{1,2}$ MB BCh, BSc (Epidemiology), \\ MSc (Clinical Epidemiology); Y Pillay, ${ }^{3}$ PhD; J Moodley, ${ }^{4,5}$ MB ChB, FRCOG, FCOG (SA), MD; B Madaj, ${ }^{6}$ MA, PhD; \\ C Ameh, ${ }^{6}$ PhD, MPH, MBBS, FWACS (OBGYN), FRSPH, FRCOG; N van den Broek, ${ }^{6}$ PhD, FRCOG, DTM\&H, MBBS \\ ${ }^{1}$ South African Medical Research Council Maternal and Infant Health Care Strategies Unit, Faculty of Health Sciences, University of Pretoria, \\ South Africa \\ ${ }^{2}$ Department of Obstetrics and Gynaecology, Faculty of Health Sciences, University of Pretoria, South Africa \\ ${ }^{3}$ Deputy Director-General: Programmes, National Department of Health, South Africa \\ ${ }^{4}$ Chairman: Emergency Obstetric Simulation Training Board, South Africa \\ ${ }^{5}$ Chairman: National Committee for Confidential Enquiries into Maternal Deaths in South Africa \\ ${ }^{6}$ Centre for Maternal and Newborn Health, Liverpool School of Tropical Medicine, Pembroke Place, Liverpool, UK
}

Corresponding author: R C Pattinson (robert.pattinson@up.ac.za)

\begin{abstract}
Background. Poor emergency obstetric care has been shown by national confidential enquiries into maternal deaths to contribute to a number of maternal deaths in South Africa.

Objectives. To assess whether a structured training course can improve knowledge and skills and whether this can influence the capacity of a healthcare facility to provide basic and comprehensive emergency obstetric care signal functions.

Methods. A baseline survey was conducted to assess the seven basic emergency obstetric and neonatal care signal functions in 51 community health centres (CHCs) and the nine comprehensive emergency care signal functions in 62 district hospitals (DHs). A reassessment was conducted 1 year after saturation training had been provided in each district. The delegates were trained using a structured training programme (Essential Steps in Managing Obstetric Emergencies, ESMOE) and their knowledge and skills were tested before and after the training. Saturation training was considered to have been achieved once $80 \%$ of the healthcare professionals involved in maternity care had been trained.

Results. There was a significant improvement in the knowledge and skills of doctors, namely by $16.8 \%$ and $32.8 \%$, respectively, of advanced midwives by $13.7 \%$ and $29.0 \%$, and of professional nurses with midwifery by $16.1 \%$ and $31.2 \%$. The seven basic emergency care functions improved from $60.8 \%$ to $67.8 \%$ in the CHCs and from $90.7 \%$ to $92.5 \%$ in the DHs before and after training. If the two signal functions that are not within the scope of practice of professional nurses with midwifery are excluded (viz. assisted delivery and manual vacuum aspiration), the functionality of CHCs increased from $85.1 \%$ to $94.9 \%$.

Conclusions. The ESMOE training programme improved knowledge and skills, but there was a modest improvement in the functionality of the facilities. Improvement in functionality requires changes in the structure of the health system, including changing the scope of practice of professional nurses with midwifery and employing more advanced midwives in CHCs.
\end{abstract}

S Afr Med J 2018;108(9):748-755. DOI:10.7196/SAMJ.2018.v108i9.13073

Emergency obstetric care is a package of medical and surgical lifesaving interventions (measured by critical 'signal functions') that are required to treat major direct causes of maternal mortality. ${ }^{[1]} \mathrm{It}$ was developed by the World Health Organization (WHO) and has been endorsed internationally by all United Nations organisations. The package was first developed and tested in 1992 and published as Guidelines for Monitoring the Availability and Use of Obstetric Services. ${ }^{[2]}$ It was reviewed and modified in 2009 and published as Monitoring Emergency Obstetric Care: A Handbook..$^{[3]}$

Each life-saving service, as measured by a signal function, is important in maternal and neonatal care at facility level. There are seven basic emergency obstetric and neonatal care (BEmONC) signal functions: intravenous (IV) antibiotics, oxytocin, magnesium sulphate, manual removal of the placenta, manual vacuum aspiration, assisted delivery and bag-and-mask ventilation. The nine comprehensive emergency obstetric and neonatal care (CEmONC) signal functions include the BEmONC functions together with caesarean delivery and blood transfusion. ${ }^{[4-7]}$
A rapid drop in mortality can be achieved by ensuring that lifesaving services are available, correctly used and accessible to the community. ${ }^{[3]}$ The signal functions, which are easily measured, are markers of these life-saving services. The capacity of healthcare facilities to provide emergency obstetric care when complications occur during pregnancy, birth or the postpartum period can be determined by assessing signal functions. This knowledge can be used to identify gaps in availability of essential obstetric care and to catalyse the changes necessary to improve the service.

\section{Objectives}

To determine whether a structured training programme could: (i) improve the knowledge and skills of healthcare professionals providing emergency obstetric and neonatal care (EmONC); and (ii) improve the functionality (availability) of basic and comprehensive emergency obstetric and neonatal care in community health centres (CHCs) and district hospital (DHs) across 12 districts with the highest maternal mortality burden in South Africa (SA). 


\section{Methods \\ Setting}

This study was conducted in the 12 'most-in-need' districts in SA to improve the emergency care of pregnant women and their babies. These 12 districts were identified by means of a scoring system based on the institutional maternal mortality ratio, the actual number of maternal deaths and the stillbirth rate of each district. The 12 selected districts contributed half of all the maternal deaths occurring in SA, excluding the seven districts in metropolitan areas with medical schools.

\section{Participants}

Participants in this study were healthcare professionals involved in maternity care in all institutions providing maternity care in each of the 12 districts identified for inclusion in the structured training programme.

\section{The intervention}

The emergency obstetric and neonatal care programme in SA is known as the Essential Steps in Managing Obstetric Emergencies and Essential Obstetric Simulation Training programme (ESMOEEOST) and includes 'skills-and-drills'-type training. The ESMOEEOST programme was adapted from the Emergency Obstetric and Early Newborn Care training package developed by the Centre for Maternal and Newborn Health at the Liverpool School of Tropical Medicine (CMNH-LSTM). ${ }^{[4,8]}$

The aim of the programme was to reduce maternal and perinatal deaths by improving the availability and quality of obstetric and neonatal emergency care. The content of the 12-module ESMOE training package included topics on preventing the direct causes of maternal death, such as eclampsia and postpartum haemorrhage, and reducing perinatal deaths by improving labour care and neonatal resuscitation. One of the modules was on the prevention of motherto-child transmission of HIV, and this was used to update the participants on the frequently changing protocols for managing women infected with HIV.

The ESMOE master trainers were a combination of trained and certified volunteer faculty from the CMNH-LSTM database in the UK and SA master trainers who were mostly district clinical specialists. The 'saturation training' approach used involved training at least $80 \%$ of all healthcare professionals from the healthcare institutions in the 12 study districts. In each district, two ESMOE courses were run per week over a period of 6 - 9 weeks: a 3-day training course for doctors and midwives from DHs and above, and a 2-day course for doctors and midwives from CHCs. The training, which started in November 2012 and finished in March 2014, was mostly conducted at off-site venues away from the hospital or $\mathrm{CHC}$, and the staff rotated so that they could all attend the course. Training in the 12 districts took place in random order. To achieve saturation, training continued for 2 months in each district.

\section{Data collection}

For this part of the study, a cross-sectional before-after design approach was used for data collection and analysis.

Before the intervention began, an on-site baseline assessment of each district was carried out, with special reference to health facilities' ability to perform BEmONC in CHCs and CEmONC in DHs. Data were collected using a researcher-administered questionnaire adapted from the standard WHO EmONC assessment tool. ${ }^{[3]}$ The same data collection exercise was repeated 1 year after the saturation training in all 133 health facilities in the 12 districts. The same team collected data before and after the training.

Before and immediately after each training workshop, data were collected from all participants on changes in knowledge and skills. Participants completed a question paper consisting of 50 true/false statements, apart from six randomly selected participants in each workshop who were allocated to the skills assessment. The test questions were on each of the 10 modules. The questions were based on what all clinicians were expected to know, irrespective of the type of facility in which they worked. The same held true for the six skills that were assessed (partogram $\times 2$, shoulder dystocia, neonatal resuscitation, assisted delivery and cardiotocography).

Theoretically, a candidate could obtain a mark of $50 \%$ just by guessing. To compensate for this, the marks were adjusted to a knowledge percentage using the following formula: knowledge mark $(\%)=(2 x-100)$, where $x$ is the MCQ mark (\%). The skills were assessed at live stations according to the number of actions covered, with the final marks converted to a percentage. Pre- and post-test marks in each district were compared using the paired $t$-test, with $p<0.05$ indicating statistical significance.

\section{Results}

A total of 3271 healthcare professionals were trained (645 doctors, 303 advanced midwives, 2130 professional nurses and 193 others/ non-categorised). Eighty percent or more of all maternity care providers in all 12 districts were trained.

A total number of 346 training workshops were held (210 3-day and 1362 -day workshops). About 94\% ( $n=3069)$ of those trained were assessed by means of an MCQ test (75\% or $n=2306)$ or a skills test $(25 \%$ or $n=764)$. Table 1 gives an overview of the number of participants trained and assessed for knowledge and skills.

\section{Knowledge and skills assessment}

Table 2 summarises the analysis of the before-and-after knowledge and skills scores for doctors, advanced midwives and professional nurses. The 'other/non-categorised' participants were excluded from the analysis. (The supplement to this article, 'Detailed knowledge and skills scores and signal functions, before and after training, available at the end of this online version, contains a detailed breakdown of the before-and-after scores for knowledge per module and for the six skills that were tested.)

Table 1. Overview of numbers of health professionals trained and tested

\begin{tabular}{|c|c|c|c|c|c|c|c|c|c|}
\hline \multirow[b]{2}{*}{ Professional category } & \multicolumn{3}{|c|}{ Total trained } & \multicolumn{3}{|c|}{ Total MCQ tests } & \multicolumn{3}{|c|}{ Total skills tests } \\
\hline & 3-day & 2-day & Total & 3-day & 2-day & Total $^{*}$ & 3-day & 2-day & Total $^{\dagger}$ \\
\hline Doctor & 573 & 72 & 645 & 406 & 36 & 413 & 167 & 36 & 189 \\
\hline Advanced midwife & 213 & 90 & 303 & 180 & 71 & 239 & 33 & 19 & 52 \\
\hline Professional nurse & 1011 & 1119 & 2130 & 796 & 797 & 1521 & 215 & 322 & 497 \\
\hline Other/non-categorised & 103 & 90 & 193 & 89 & 58 & 133 & 14 & 32 & 43 \\
\hline Total & 1900 & 1371 & 3271 & 1471 & 962 & 2306 & 429 & 409 & 764 \\
\hline
\end{tabular}


Table 2. Knowledge and skills assessment, per type and professional category

\begin{tabular}{|c|c|c|c|c|c|c|c|c|}
\hline \multirow[b]{2}{*}{ Professional category } & \multicolumn{3}{|c|}{ Knowledge $(\%)^{*}$} & \multirow[b]{2}{*}{$p$-value } & \multicolumn{3}{|c|}{ Skills (\%) } & \multirow[b]{2}{*}{$p$-value } \\
\hline & $N$ & Before & After & & $N$ & Before & After & \\
\hline Doctor & 413 & 50.9 & 67.6 & $<0.000$ & 189 & 45.4 & 78.2 & $<0.000$ \\
\hline Advanced midwife & 239 & 34.8 & 48.4 & $<0.000$ & 52 & 44.5 & 73.5 & $<0.000$ \\
\hline Professional nurse & 1521 & 26.0 & 42.4 & $<0.000$ & 497 & 35.9 & 67.1 & $<0.000$ \\
\hline Overall & 2173 & 31.8 & 47.8 & $<0.000$ & 738 & 38.6 & 70.5 & $<0.000$ \\
\hline
\end{tabular}

Table 3. Number of signal functions at baseline and reassessment 1 year after saturation training

\begin{tabular}{|c|c|c|c|c|}
\hline \multirow[b]{2}{*}{ Number of functions } & \multicolumn{2}{|c|}{ Community health centres $(N=51)$} & \multicolumn{2}{|c|}{ District hospitals $(N=62)$} \\
\hline & Baseline (\%) & Re-baseline (\%) & Baseline (\%) & Re-baseline (\%) \\
\hline 9 & - & - & 46.8 & 62.9 \\
\hline 8 & - & - & 80.6 & 82.3 \\
\hline 7 & 0.0 & 3.9 & 91.6 & 90.3 \\
\hline 6 & 5.9 & 9.8 & 96.8 & 96.3 \\
\hline 5 & 49.0 & 64.7 & 100 & 100 \\
\hline 4 & 94.1 & 100 & 100 & 100 \\
\hline 3 & 100 & 100 & 100 & 100 \\
\hline
\end{tabular}

There was a significant improvement in knowledge and skills of doctors, namely by $16.8 \%$ and $32.8 \%$, respectively, of advanced midwives by $13.7 \%$ and $29.0 \%$, and of professional nurses with midwifery by $16.1 \%$ and $31.2 \%$. (For further details, see the supplement.)

\section{Functionality of health facilities}

With regard to the number of signal functions, there were modest improvements in the ability of CHCs and DHs to perform BEmONC and CEmONC, respectively. Of the 18 regional and tertiary hospitals, 16 had previously been able to do all nine functions, but two were not able to provide an assisted delivery service. At the assessment after 12 months, all 18 were able to do all the functions.

Table 3 provides an overview of changes in the number of signal functions in $\mathrm{CHCs}$ and $\mathrm{DHs}$ before and after saturation training. The seven $\mathrm{BEmONC}$ functions improved from an average of $60.8 \%$ to $67.8 \%$ in the CHCs before and after saturation training ( $p=0.001$ ); in the DHs these seven functions improved from an average of $90.7 \%$ to $92.5 \%$ ( $p=0.05$ ). If the two signal functions that do not fall within the scope of practice of the professional nurses with midwifery are excluded (viz. assisted delivery and manual vacuum aspiration), ${ }^{[9]}$ functionality with regard to CHCs rose from $85.1 \%$ to $94.9 \%$. For other individual functions there was an increase of $26.5 \%, 19.4 \%$ and $9.5 \%$ for providing IV antibiotics, manual removal of the placenta, and bag-and-mask ventilation, respectively.

Figs 1 and 2 illustrate the change in functionality from baseline to reassessment 1 year after saturation training with regard to each of the signal functions. The lack of change in the signal functions of assisted deliveries and manual vacuum aspiration is clearly demonstrated. More details on the change in each of the functions are provided in the supplement.

\section{Discussion}

In addition to determining the effect of ESMOE training on the knowledge and skills of health professionals, this study also explored a potential relationship between the improvement in knowledge and skills and the improvement in the signal functions of healthcare facilities. In terms of the expanded version of Kirkpatrick's four-level model for evaluating the effectiveness of a training programme, ${ }^{[10]}$

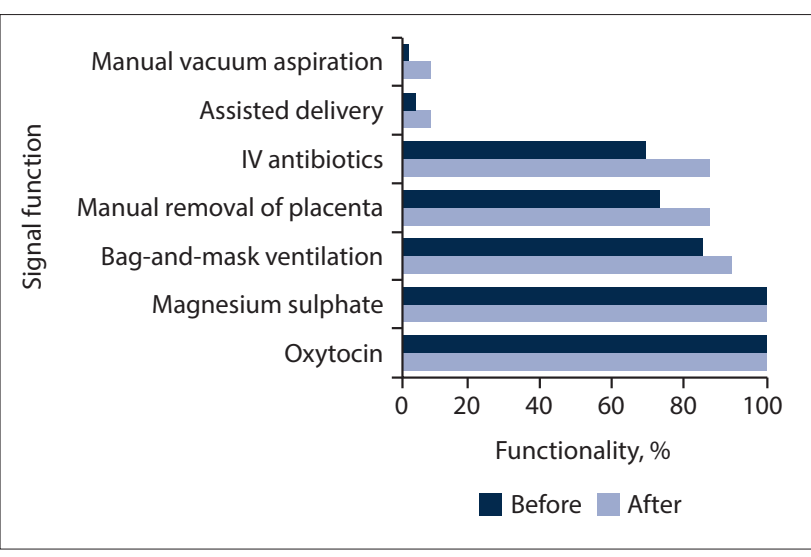

Fig. 1. Change in signal functions of community health centres $(\mathrm{N}=51)$. $(I V=$ intravenous. $)$

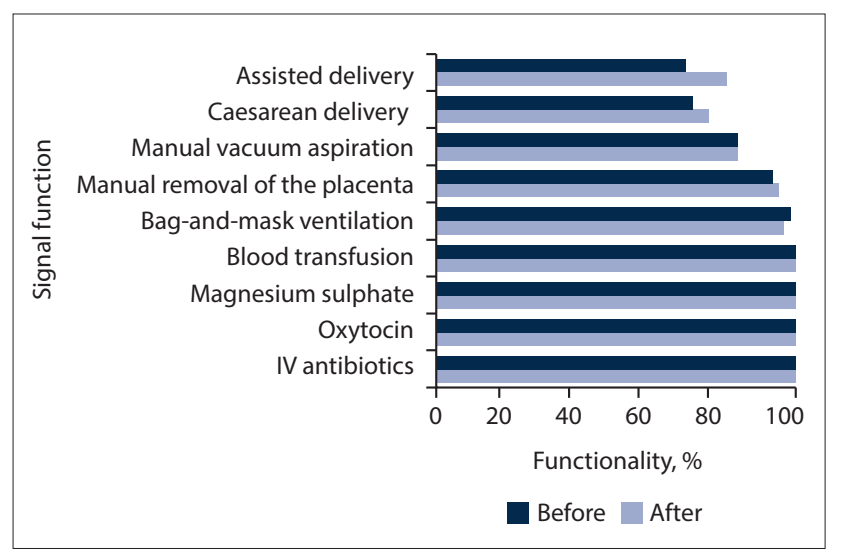

Fig. 2. Change in signal functions of district hospitals $(\mathrm{N}=62)$. (IV = intravenous.)

we were able to demonstrate a significant change at the second level (learning) after the increase in participants' knowledge and skills as a result of the ESMOE training programme. Significant changes in signal functions are measured at the fourth (outcome) level as part of process change in quality of care. ${ }^{[10]}$ The use of 
manual vacuum aspiration and assisted delivery is currently not included in the South African Nursing Council's scope of practice of professional nurses with midwifery, ${ }^{[9]}$ and change in these functions was therefore minimal. However, the improvements in the provision of IV antibiotics, manual removal of the placenta and bag-and-mask ventilation - changes that, in the SA context, could be influenced by training - were increased. Overall, the changes were not sufficiently significant to support a claim that the ESMOE training was effective in changing the number of signal functions.

Many emergency obstetrics training programmes include an evaluation of the increase in participants' knowledge and skills. The literature mainly reports a significant increase after training, ${ }^{[11-13]}$ as did our study. Some studies also report on knowledge and/or skills retention after a certain period of time, ${ }^{[14-16]}$ with some studies recommending the continuation of training and an investigation into the frequency and intensity of follow-up training. ${ }^{[16]}$ While the ESMOE training programme is effective in improving knowledge and skills, it is clear that the baseline knowledge and skills of the delegates were low. Despite the increase in knowledge and skills, the level of both remained low. This indicates the necessity for continuing professional development for both doctors and professional nurses. Annual refresher courses are essential to maintain the knowledge and skills of all maternity care providers.

A systematic review by Nyamtema et al. ${ }^{[17]}$ reports on programmes with multiple interventions that included EmONC and that impacted positively on maternal health outcomes and quality of care. With the marginal improvement in signal functions, our study demonstrated that training on its own can bring about some benefits, but that it does not have the necessary effect on structural changes in the health system. There are barriers to improving care that must also be removed before changes in functionality can occur. Many CHCs are only able to provide five signal functions because of the limited scope of practice of nurses with midwifery ${ }^{[9]}$ In a study of nine African countries it was found that different types of nurse/midwife cadres performed different numbers of signal functions, with low proportions performing manual removal of the placenta, removal of retained products and assisted vaginal delivery. In most countries there were discrepancies between the number of signal functions allowed by legislation and the number of functions performed by nurses and midwives ${ }^{[18]}$ One study showed the value of task shifting. Whereas before training only $43 \%$ of basic and $56 \%$ of comprehensive emergency care facilities were able to perform the expected signal functions, after training all facilities were able to perform 100\% of expected signal functions. This was achieved by having trained midwives performing skilled tasks usually performed by medical doctors. $^{[12]}$

\section{Study limitations}

Our study focused on the 12 'most-in-need' districts in SA, where one might have expected the training to have the biggest effect on the knowledge and skills of health professionals. A limitation of the study was that measurement of knowledge and skills retention after a period of time was not included in the design. The more dysfunctional a district's maternity services were, the more difficult it may have been to change signal functions without other accompanying health systems-strengthening activities. The result has been minimal change, where change might have been greater in a more functional unit. During the whole period of training, other training initiatives were conducted on screening and treating pregnant women with HIV infection. Towards the end some districts also used the Helping Babies Breathe programme, ${ }^{[19]}$ a country-owned and country-led public-private partnership that is co-ordinated through ministries of health. The classification of district hospitals was kept the same throughout the study, although during the same period some DHs were reclassified as $\mathrm{CHCs}$ because of rationalisation of services. This could have falsely lowered the impact.

The implementation team did not have a mandate to change the district health system or the regulations of the Nursing Council. Without changes to the way CHCs are staffed, it is not possible to influence the signal functions in these facilities. This limits the effect of the study, but also indicates the need for a broader approach to training as part of multiple intervention packages that can change the health system positively. ${ }^{[16,17]}$

\section{Conclusions}

The ESMOE training programme improved knowledge and skills, but the functionality of the facilities showed modest improvement. To improve functionality of facilities, changes in the structure of the health system need to be made, including changing the scope of practice of professional nurses with midwifery and employing more advanced midwives in the CHCs. SA has too many healthcare facilities for its population, but sufficient midwifery staff to safely manage the population per district. ${ }^{[20,21]}$ Consolidating services to ensure that advanced midwives are stationed at $\mathrm{CHCs}$ and a critical mass of doctors at DHs could therefore significantly improve basic and comprehensive emergency care.

Acknowledgements. We would like to thank all the master trainers, especially those from the UK who spent their holidays training for 2 weeks in SA. A special thank you goes to Cathy Bezuidenhout (project manager) and Nthabiseng Mokatsi, Sidney Mokatsi and Danie Thirion (course coordinators) for controlling the logistics so well.

Author contributions. RCP and $\mathrm{NvdB}$ conceptualised the study and supervised the implementation. JMa was responsible for monitoring and evaluation and supported statistical analysis. YP facilitated access to health systems and health facilities. JMo provided oversight for the project and was involved in the conceptualisation of the study. CA was involved in programme design, monitoring and writing. $\mathrm{BM}$ was involved in statistical analyses. A-MB provided technical support and was involved in EOST activities. RCP and A-MB drafted the initial manuscript, on which all other authors gave input. All authors approved the final version of the manuscript for submission.

Funding. The study was supported by funding from DFID South Africa (contract no. 200295-102) and DFID Making it Happen (contract no. 202945-101).

Conflicts of interest. None.

\footnotetext{
Paxton A, Maine D, Freedman L, Fry D, Lobis S. The evidence for emergency obstetric care. Int J Gynaecol Obstet 2005;88(2):181-193. https://doi.org/10.1016/ji.igo.2004.11.026

2. United Nations Children's Fund (UNICEF), World Health Organization (WHO), United Nations Population Fund (UNFPA). Guidelines for Monitoring the Availability and Use of Obstetric Services. New York: UNICEF, 1997.

3. United Nations Children's Fund (UNICEF), United Nations Population Fund (UNFPA), World Health Organization (WHO). Monitoring Emergency Obstetric Care: A Handbook. Geneva: WHO, 2009.

4. Ameh C, Kerr R, Madaj B, et al. Knowledge and skills of healthcare providers in sub-Saharan Africa and Asia before and after competency-based training in emergency obstetric and early newborn care. PLoS One 2016;11(12):e0167270. https://doi.org/10.1371/journal.pone.0167270

5. Ameh C, Msuya S, Hofman J, Raven J, Mathai M, van den Broek N. Status of emergency obstetric care in six developing countries five years before the MDG targets for maternal and newborn health. PLoS One 2012;7(12):e49938. https://doi.org/10.1371/journal.pone.0049938

6. Holmer $\mathrm{H}$, Oyerinde $\mathrm{K}$ Meara J Gillies $\mathrm{R}$ Liliestrand J Hagander L The global met need for emergency . Holmer H, Oyerinde K, Meara J, Gillies R, Liljestrand J, Hagander L. The global met need for emergency obstetric care: A systematic review. BJOG 2014;122(2):183-189. https://doi.org/10.1111/147 0528.13230

Organization (WHO). Managing Complications in Pregnancy and Childbirth: A Guide for Midwives and Doctors (WHO/RHR/00). Geneva: WHO, 2003.

8. Van den Broek N, ed. Life Saving Skills Manual: Essential Obstetric and Newborn Care. 2nd ed. London: Royal College of Obstetricians and Gynaecologists, 2007
} 
9. South Africa. Nursing Act No. 33 of 2005. Regulations relating to the approval of and the minimum requirements for the education and training of a learner leading to registration in the category midwife. Government Gazette No. 38095, 2014. (Published under Government Notice R786, 13 October 2014.)

10. Bergh A-M, Baloyi S, Pattinson R. What is the impact of multi-professional emergency obstetric and neonatal care training? Best Pract Res Clin Obstet Gynaecol 2015;29(8):1028-1043. https://doi. org/10.1016/j.bpobgyn.2015.03.017

11. Grady K, Ameh C, Adegoke A, Kongnyuy E, Dornan J, Falconer T. Improving essential obstetric and newborn care in resource-poor countries. J Obstet Gynaecol 2011;31(1):18-23. https://doi.org/10.310 9/01443615.2010.533218

12. Ameh C, Adegoke A, Hofman J, Ismail FM, Ahmed FM, van den Broek N. The impact of emergency obstetric care training in Somaliland, Somalia. Int J Gynaecol Obstet 2012;117(3):283-287. https://doi. org/10.1016/ji.ijgo.2012.01.015

13. Raven J, Utz B, Roberts D, van den Broek N. The 'Making it Happen' programme in India and Bangladesh. BJOG 2011;118(Suppl 2):100-103. https://doi.org/10.1111/j.1471-0528.2011.03119.x

14. Tang JH, Kaliti C, Bengtson A, et al. Improvement and retention of emergency obstetrics and neonatal care knowledge and skills in a hospital mentorship program in Lilongwe, Malawi. Int J Gynaecol Obstet 2016;132(2):240-243. https://doi.org/10.1016/j.ijgo.2015.06.062

15. Mirkuzie AH, Sisay MM, Bedane MM. Standard basic emergency obstetric and neonatal care training in Addis Ababa: Trainees reaction and knowledge acquisition. BMC Med Educ 2014;14:201. https:// doi.org/10.1186/1472-6920-14-201
16. Nelissen E, Ersdal H, Mduma E, et al. Helping mothers survive bleeding after birth: Retention of knowledge, skills, and confidence nine months after obstetric simulation-based training. BMC knowledge, skills, and confidence nine months after obstetric simulation-base
Pregnancy Childbirth 2015;15:190. https://doi.org/10.1186/s12884-015-0612-2

17. Ny cym countries: A systematic review of packages, impacts and factors for change. BMC Pregnancy Childbirt

18. Adegoke A, Utz B, Msuya SE, van den Broek N. Skilled birth attendants: Who is who? A descriptive study of definitions and roles from nine Sub Saharan African countries. PloS One 2012;7(7):e40220. https://doi.org/10.1371/journal.pone.0040220

9. Helping Babies Breathe (HBB). https://www.oecd.org/dac/peer-reviews/Helping-Babies-Breathe.pdf (accessed 6 August 2018)

20. Pattinson R, Makin J, Pillay Y, van den Broek N, Moodley J. Basic and comprehensive emergency obstetric and neonatal care in 12 South African health districts. S Afr Med J 2015;105(4):256-260. https://doi.org/10.7196/SAMJ.9181

21. Pattinson R. Safety versus accessibility in maternal and perinatal care. S Afr Med J 2015;105(4):261 265. https://doi.org/10.7196/SAMJ.9182

Accepted 24 May 2018 
Supplement. Detailed knowledge and skills scores and signal functions, before and after training

Mean MCQ scores of delegates $(n=2173)$ per module topic

\begin{tabular}{|l|r|r|r|}
\hline & Mean Before & Mean After & p value \\
\hline Eclampsia & 4.373 & 4.608 & $<.0001$ \\
\hline Haemorrhage & 3.304 & 3.890 & $<.0001$ \\
\hline Obstructed labour & 3.430 & 3.684 & $<.0001$ \\
\hline Sepsis & 3.123 & 3.170 & .046 \\
\hline Assisted delivery & 3.154 & 3.680 & $<.0001$ \\
\hline Obstetric complications & 3.314 & 3.939 & $<.0001$ \\
\hline Surgical skills & 3.143 & 3.462 & $<.0001$ \\
\hline Post-abortion sepsis & 2.733 & 3.286 & $<.0001$ \\
\hline CPR & 2.590 & 3.266 & $<.0001$ \\
\hline Neonatal resuscitation & 3.327 & 3.957 & $<.0001$ \\
\hline Total Score & 32.951 & 36.941 & $<.0001$ \\
\hline Knowledge \% & 65.9 & 73.9 & \\
\hline $\begin{array}{l}\text { Knowledge\% (as per } \\
\text { calculation*) }\end{array}$ & 31.8 & 47.8 & \\
\hline
\end{tabular}

$*(2 * \%$ score $)-100$ - See text

Change in knowledge scores, per health care professional category

\begin{tabular}{|l|r|r|r|r|r|r|}
\hline & \multicolumn{2}{|c|}{ Doctor } & \multicolumn{2}{c|}{ Advanced midwife } & \multicolumn{2}{c|}{ Professional nurse } \\
\hline & $\mathbf{n}$ & $\mathbf{\%}$ & $\mathbf{n}$ & $\mathbf{\%}$ & $\mathbf{n}$ & $\mathbf{\%}$ \\
\hline Improved & 361 & 87.4 & 189 & 79.1 & 1230 & 80.9 \\
\hline Stayed the same & 24 & 5.8 & 23 & 9.6 & 85 & 5.6 \\
\hline Deteriorated & 28 & 6.8 & 27 & 11.3 & 206 & 13.5 \\
\hline Subtotal & 413 & 100 & 239 & 100.0 & 1521 & 100.0 \\
\hline Did not take both tests & 29 & & 12 & & 72 & \\
\hline TOTAL & $\mathbf{4 4 2}$ & & $\mathbf{2 5 1}$ & & $\mathbf{1 5 9 3}$ & \\
\hline
\end{tabular}


Change in skills scores, per health care professional category

\begin{tabular}{|c|c|c|c|c|c|c|c|c|c|}
\hline \multirow[t]{2}{*}{ Skill } & \multirow{2}{*}{$\begin{array}{c}\text { Before (B) } \\
\text { and } \\
\text { After (A) }\end{array}$} & \multicolumn{2}{|c|}{ All } & \multicolumn{2}{|c|}{ Doctors } & \multicolumn{2}{|c|}{$\begin{array}{l}\text { Advanced } \\
\text { midwives }\end{array}$} & \multicolumn{2}{|c|}{$\begin{array}{c}\text { Professional } \\
\text { nurses }\end{array}$} \\
\hline & & Mean & $\mathbf{N}$ & Mean & $\mathbf{N}$ & Mean & $\mathbf{N}$ & Mean & $\mathbf{N}$ \\
\hline \multirow{2}{*}{ Partogram } & B Skills1 & 4.1 & 253 & 4.5 & 68 & 5.4 & 16 & 4.0 & 169 \\
\hline & A Skills 1 & 6.6 & 253 & 7.1 & 68 & 7.2 & 16 & 6.3 & 169 \\
\hline \multirow{2}{*}{$\begin{array}{l}\text { Shoulder } \\
\text { dystocia }\end{array}$} & B Skills2 & 3.8 & 259 & 4.5 & 68 & 4.5 & 16 & 3.4 & 175 \\
\hline & A Skills 2 & 8.4 & 259 & 8.8 & 68 & 9.1 & 16 & 8.2 & 175 \\
\hline \multirow{2}{*}{$\begin{array}{l}\text { Neonatal } \\
\text { resuscitation }\end{array}$} & B Skills 3 & 4.8 & 251 & 5.3 & 59 & 5.1 & 15 & 4.5 & 177 \\
\hline & A Skills 3 & 8.1 & 251 & 9.0 & 59 & 8.7 & 15 & 7.7 & 177 \\
\hline \multirow{2}{*}{$\begin{array}{l}\text { Assisted } \\
\text { delivery }\end{array}$} & B Skills 4 & 3.2 & 247 & 3.9 & 64 & 3.7 & 21 & 2.8 & 162 \\
\hline & A Skills 4 & 7.9 & 247 & 8.6 & 64 & 7.5 & 21 & 7.7 & 162 \\
\hline \multirow{2}{*}{ Partogram } & B Skills 5 & 5.2 & 235 & 6.0 & 56 & 5.6 & 15 & 4.9 & 164 \\
\hline & A Skills 5 & 7.2 & 235 & 7.7 & 56 & 7.8 & 15 & 6.9 & 164 \\
\hline \multirow{2}{*}{ CTG } & B Skills 6 & 2.5 & 240 & 3.4 & 63 & 3.1 & 20 & 2.0 & 157 \\
\hline & A Skills 6 & 4.2 & 240 & 5.7 & 63 & 5.0 & 20 & 3.6 & 157 \\
\hline \multirow{2}{*}{ All } & Total B (\%) & 39.0 & 738 & 45.5 & 189 & 45.0 & 52 & 35.9 & 497 \\
\hline & Total A (\%) & 70.5 & 738 & 78.2 & 189 & 73.5 & 52 & 67.1 & 497 \\
\hline
\end{tabular}


Signal functions before and after saturation training

\begin{tabular}{|l|c|c|c|c|}
\hline \multirow{2}{*}{$\begin{array}{l}\text { Community Health } \\
\text { Centres }\end{array}$} & \multicolumn{2}{|c|}{ Before } & \multicolumn{2}{c|}{ After } \\
\hline & N & \% & N & $\%$ \\
\hline Oxytocin & 51 & 100.0 & 51 & 100.0 \\
\hline Magnesium sulphate & 51 & 100.0 & 51 & 100.0 \\
\hline Bag and mask ventilation & 42 & 82.4 & 46 & 90.2 \\
\hline Manual removal placenta & 36 & 70.6 & 43 & 84.3 \\
\hline IV antibiotics & 34 & 66.7 & 43 & 84.3 \\
\hline Assisted delivery & 2 & 3.9 & 4 & 7.8 \\
\hline Manual vacuum aspiration & 1 & 2.0 & 4 & 7.8 \\
\hline
\end{tabular}

\begin{tabular}{|l|c|c|c|c|}
\hline District Hospitals & \multicolumn{2}{|c|}{ Before } & \multicolumn{2}{c|}{ After } \\
\hline & N & \% & N & \% \\
\hline IV antibiotics & 62 & 100.0 & 62 & 100.0 \\
\hline Oxytocin & 62 & 100.0 & 62 & 100.0 \\
\hline Magnesium sulphate & 62 & 100.0 & 62 & 100.0 \\
\hline Blood transfusion & 62 & 100.0 & 62 & 100.0 \\
\hline Bag and mask ventilation & 61 & 98.4 & 60 & 96.8 \\
\hline Manual removal placenta & 58 & 93.5 & 59 & 95.2 \\
\hline Manual vacuum aspiration & 52 & 83.9 & 52 & 83.9 \\
\hline Caesarean delivery & 44 & 71.0 & 47 & 75.8 \\
\hline Assisted delivery & 43 & 69.4 & 50 & 80.6 \\
\hline
\end{tabular}

